\title{
FUNCTIONAL CONSIDERATIONS FOR TREATING NONSTICK COATING HOUSEHOLD COOKWARE
}

\author{
Muhammad Al-Awami Muhammad *
}

Department of Measurement and Ornaments - Standard Arts

\begin{abstract}
The home cooking utensil industry has developed in the recent period in a clear way, which has led to the multiplicity of raw materials and functions of these pots, and in addition to that, many surface treatment processes with different functions have developed for the process of preparing and preserving foods, and among the coatings that have spread in the recent period was what is known as non-coating Nonstick, which is used to paint the inner surfaces of cooking utensils, especially those that have direct contact with foods. It has been used for many materials such as aluminum, its alloys, iron and its alloys. Non-stick coatings in the past were based on Teflon compounds (Tefal) as one of the most important coatings. The inner surfaces of cooking utensils, especially those used in the preparation of certain foods such as baked goods, desserts and cakes.

And other foods that can stick to food, enamel coating and anodizing coating were made with thick layers of non-stick coatings, which were of a lower degree than the quality of Tefal in resisting food sticking, then non-stick coatings developed and what is known as ceramic coating appeared, especially applied in a way. Sol-Gel, which is considered an advanced non-stick coating, is suitable for most of the raw materials of cookware for preparing different types of food. The multiplicity of non-stick coating layers leads to an essential need to direct the user to choose the best non-stick layers that are safe to perform their functions. Keywords

NONSTICK COATING- HOUSEHOLD -COOKWARE
\end{abstract}

\section{Introduction}

Knowing the non-stick coatings and their functional importance for home cookware and identifying the different treatments for the surfaces of the cookware, especially the inner ones, and the most important advantages and disadvantages of the non-stick layers.

Determining the difference between the layers of non-stick coating eliminates the state of hesitation and controversy when the user is buying home cooking utensils, especially those with a non-stick inner surface.

\section{Methodology}

\section{Descriptive and analytical}

1- The concept of non-stick coating and how it works:

Non-stick coatings are used for an important function when preparing food in metal cookware, so there are many layers to achieve this function to meet the market requirements of the user's

\footnotetext{
*Corresponding author: author@institute.xxx
} 
needs, in addition to knowing what you want to do and the different treatments helps to simplify the task, even if it is arduous.

What is a non-stick coating? How do you know which paint is suitable for your product? Even if it wasn't you who chose the paint, how would you know that you were getting paid?

These questions need clear answers so that the user can choose the appropriate product for his needs, but before determining clear answers to these questions, it is necessary to know and determine the causes of food sticking in the cooking utensils, which are: -

- A high temperature while cooking food.

- Not concentrating the heat on the base and distributing it appropriately in all parts of the container.

- The food contains easy-to-burn materials such as starches, and others.

- Not turning the food over regularly and well while cooking.

- Use of materials for cooking pots with good heat conductivity.

- Low fat and oil content in food.

\section{Results:}

1- Resistance to adhesion to metal surfaces, which may occur through the application of a secondary coating (oil layer), which causes poor adhesion to the materials that can be easily separated or prevented from sticking by permanent applications, to a coating that prevents sticking.

2- Cooking utensils are made of various materials such as copper and its alloys, aluminum and its alloys, iron and its alloys, which make it difficult to choose the best, especially in non-stick pots with food.

3- Cooking and coating processes are divided into layers of adhesive coating for the inner and outer surface such as silver, gold and chrome plating, and non-stick coating for the inner surface of the cooking pots such as ceramics and taffles.

4- It is preferable to use cookware with smooth surfaces for ease of cleaning, with the dishwasher not being used for cleaning and the need to clean it after use with a soft sponge in the presence of soap or industrial detergent.

5- Not to use Teflon-coated utensils after scratching their inner surface, because they leave some parts of Teflon when preparing foods, and because they will interact with aluminum, so food is contaminated with Teflon and metal, which is harmful to health.

6- Teflon-coated cooking utensils do not withstand high temperatures more than 200 degrees Celsius, especially when they are free of oil or any other food material. 
7- Cooking utensils must be able to distribute heat quickly in all parts of the food.

8- The quality of the non-stick coating is related to several factors that depend on the number of layers that the coating is made of - the thickness of the layers of the coating - the composition of the coating - how the paint is applied on the now. - The original metal of the utensil (in addition to the thickness and quality of the metal).

9- Sol-gel technique is a chemical method used to apply ceramic materials at relatively low temperatures, based on the chemical treatment of wet materials.

10- Sol-gel technology is distinguished by many characteristics, including energy saving for low temperature use. The layers of paint are homogeneous and high purity. - Easy to obtain thick layers of paint, etc.

11- Sol's ceramic coating consists of five basic elements, which are a binder.

The binder) - coloring materials - non-stick material - backing and stiffening materials - the carrier material, which is suspended with other materials.

12- The sol-gel process technology has succeeded in applying a wide range of advanced ceramics as coating layers for cooking utensils and tableware, especially pieces.

13- The application of non-stick coating has several steps which are surface preparation, activation, filtration and application.

14- Ceramic coated pots are distinguished from Tefal pots by several properties such as environment friendly - high temperature resistance - good abrasion resistance - high gloss and good resistance to oil and liquid absorption - good spread - temperature resistance up to 450 degrees Celsius - color plethora - ease of application.

\section{References}

1- A. He Q. Liu D. G. Ivey-(2009) - Electroplating of gold from a solution containing triammonium citrate and sodium sulphite- Canada- Mater Electron pp.543-550

2- Alfred M. Weisberg,- 1994- ASM Handbook, Volume 5, Surface Engineering United States of America-pp.851-854

3- Arthur A. Tracton- 2007- coatings materials and surface coatings- by Taylor \& Francis Group,PP.29-1,29-5

4- Austrian Department of Health- (2014) Bundesministerium für Gesundheit. Aluminiumtoxikologie und gesundheitliche- Aspekte krpernaher Anwendungen. Herausgeber, Medieninhaber und- Hersteller: Bundesministerium für Gesundheit, Sektion IIRadetzkystrae 2, 1031 Wiensterreich.

5- C. Barry Carter -M. Grant Norton-2013- Ceramic Materials

6- Charles C. Broz,- D. Christopher Taylor,- Jonathan Barr, - 2016- 
7- Dr. Feng Shi -Ceramic Coatings -2012- Applications in Engineering- InTech- Janeza Trdine -Rijeka, Croatia .

8- E. Scrinzi, S. Rossi,- 2010- The aesthetic and functional properties of enamel coatings on steel. Materials \& Design - Mater-Design, Vol. 31(9), pp. 4138-4146

9- Ganesh, V.A.; Raut, H.K.; Nair, A.S.; Ramakrishna, S.- 2011- A review on self-cleaning coatings. J. Mater. Chem., PP.16304-16322.

10-Helen H. Lou- Yinlun Huang-2006- Electroplating- - Lamar University, Beaumont, Texas, Taylor \& Francis.- U.S.A.

11- John C. Oliver,,- 1994- ASM Handbook, Volume 5, Surface Engineering United States of America-pp.1344-1345

12- LeSife S chaschl- Rachel K'amenetzky-2014- Process Specification for Polytetrafluoroethylene (PTFE) -Impregnated or Codeposited Surface Treatment of Aluminum Alloys- Lyndon B. Johnson Space Center Houston, Texas-National Aeronautics and Space (NASA)- -pp.1-7

13-Masoud Bodaghi, Amin Davarpanah,- 2011- The influence of co-balt on the microstructure and adherence characteristics of enam-el on steel sheet. Processing and Application of Ceramics, 5 (4), pp. 215-222.

14-Md. Abul Hossain, Aninda Nafis Ahmed and Md. Anwar Arfien Khan-2014- Vitreous Enamel Coating on Mild Steel Substrate: Characterization and Evaluation- Volume 5, Issue 2, International Journal of Scientific \& Engineering Research,PP. 821-826

15-Milton F. Stevenson, Jr.,- 1994- ASM Handbook, Volume 5, Surface Engineering United States of America-pp.1416-1417

16- Non-stick “green” cookware: Does it measure up to manufacturers' claims?

17- -Ondik, MP, Kang, J, Bayeri, MG, Bruno, M, Golden - berg, D (2009) : Teflon larinegeal granuloma Presenting as laryn gel cancer on combined positron emission tomography and computed temograhy scanning, Journal of laryngology and otology, PP.575-8.

18- -Petrie, E.M. Abhesion-2012-The science of non-stick surfaces. Met. Finish.-, PP.110, 2831

19- Science and Engineering- Springer Science+Business Media New York 24-Ashokkumar, S.; Adler-Nissen, J.- 2011- Evaluating non-stick properties of different surface materials for contact frying. J. Food Eng.PP.105, 537-544

20- Thomas, P.- 1998- The use of fluoropolymers for non-stick cooking utensils. Surf. Coat. Int., PP. 604-609 
21- Thorsten Stahl1*, Sandy Falk2, Alice Rohrbeck2, Sebastian Georgii2, Christin Herzog1(2017)- Migration of aluminum from food-contact materials to food - a health risk for consumers? Part I of III- Kassel, Germany-Stahl et al. Environ Sci EurPP. 29-19

22- http://www.ballarini.it

23- http://www.ballarini.it

24- https://healthy-cookware.com/nonstick-cookware1/3/2019

25- https://healthy-cookware.com/nonstick-cookware1/3/2019

26-https://www.finecooking.com/article/the-science-of-nonstick-cookware

27-https://www.finecooking.com/article/the-science-of-nonstick-cookware

28-www.metalfinishing.com7/8/2019

29-www.ProductKnowledge.com4/5/2019

Received: February 02, 2019

Accepted: April 26, 2019 